\title{
A New Deep-Sea Enhydrosoma (Copepoda, Harpacticoida, Cletodidae) from the Northern Gulf of Mexico
}

\author{
Eun-Ok Park ${ }^{1,2}$, Melissa Rohal ${ }^{3,4}$ and Wonchoel Lee ${ }^{1, *(D)}$ \\ 1 Department of Life Science, College of Natural Sciences, Hanyang University, Seoul 04763, Korea; \\ peo75@gjeri.kr \\ 2 Gwangju Jeonnam Research Institute, 56, Ujeong-ro, Naju-Si, Jellanam-do 58217, Korea \\ 3 Harte Research Institute for Gulf of Mexico Studies, Texas A\&M University-Corpus Christi, \\ 6300 Ocean Drive, Corpus Christi, TX 78412, USA; mlrohal@coastal.edu \\ 4 Texas water development board, 1700 North Congress Avenue, Austin, TX 78701, USA \\ * Correspondence: wlee@hanyang.ac.kr; Tel.: +82-2-2220-0951 \\ http://zoobank.org/urn:lsid:zoobank.org:pub:B46D857A-E7C1-4DB5-AD60- \\ 16C0B670D346
}

Received: 16 October 2020; Accepted: 11 November 2020; Published: 13 November 2020

\begin{abstract}
Enhydrosoma texana sp. nov. is described from the northern Gulf of Mexico. The new species is closely related to E. parapropinquum Gómez, 2003 from northwestern Mexico. Both species share several characters including an elongated cylindrical caudal ramus, an abexopodal seta of antennae, the structure of mouthpart appendages, seta formula of thoracic legs P1-P4, the shape of the P5 exopod in the female and the apophysis structure of P3 in males. However, the new species is distinguishable from E. parapropinquum by the shape of the rostrum, number of the antennular segments, the shape of the mandibular palp, the relative lengths of the thoracic legs, the shape of the apophysis of P3 in the male, setal number and length of the P5 exopod of the female, the length of the seta on P5 in the male and the relative lengths of the caudal ramus in both sexes. This is the deepest record of a species in the genus Enhydrosoma.
\end{abstract}

Keywords: taxonomy; biodiversity; Texas; Oligotroph; MABIK

\section{Introduction}

Enhydrosoma Boeck, 1872 is one of the biggest genera in the family Cletodidae T. Scott, 1905. Gee [1] partially reviewed the taxonomic characters of the genus Enhydrosoma in the Cletodidae. Enhydrosoma species have been moved to other genera or newly erected genera within Cletodidae on several occasions [1-5]. The genus has diverse congeners, more than 53 valid species and several authors suggests a necessity for the revision of the genus since it is polyphyletic in nature [6,7].

There are few reports of species in the genus Enhydrosoma from the Gulf of Mexico; only four species (E. herrerai Bell and Kern, 1983, E. lacunae Jakubisiak, 1933, E. littorale Wells, 1967 and E. longifurcatum Sars, 1909) have been described from this region. In addition, Gómez [8,9] described four species (E. parapropinquum Gómez, 2003, E. casoae Gómez, 2003, E. solitarium Gómez, 2003 and E. brevipodum Gómez, 2004) of Enhydrosoma from the Mexican Pacific coast.

During a survey of the meiofauna of the northern Gulf of Mexico, a new species of Enhydrosoma was collected from a sediment sample. We provide a detailed description of the new species and discuss its relationship with the congeners. 


\section{Materials and Methods}

Sediment samples were collected using core tubes inside a GOMEX boxcorer. The methods of Baguley et al. [10] were adopted. Sampling stations are listed in Table 1. Harpacticoid copepods were sorted out from the meiofauna samples, and each copepod individual was dissected in lactic acid for identification. The dissected parts were mounted on slides in lactophenol as a mounting medium and sealed with transparent nail varnish. A camera lucida attached to a Leica DMLB differential interference contrast microscope was used for the illustrations of the new species. The descriptive terminology of Huys et al. [11] was used for text description; i.e., ae, aesthetasc; P1-P6, first to sixth thoracopod; exp (enp)-1 (2,3), proximal (middle, distal) segment of the exopod or endopod ramus. The type specimens have been deposited in the collections of the Marine Biodiversity Institute of Korea (MABIK). Scale bars in figures are in $\mu \mathrm{m}$.

Table 1. Sampling stations in the deep sea of the Northern Gulf of Mexico.

\begin{tabular}{|c|c|c|c|c|c|}
\hline Station & Latitude & Longitude & Depth (m) & Sampling Date & Specimens \\
\hline MT5 & $27^{\circ} 33^{\prime} 28^{\prime \prime} \mathrm{N}$ & $88^{\circ} 65^{\prime} 60^{\prime \prime} \mathrm{W}$ & 2280 & 4 June 2000 & 19 \\
\hline $\mathrm{S} 36$ & $28^{\circ} 91^{\prime} 94^{\prime \prime} \mathrm{N}$ & $87^{\circ} 67^{\prime} 03^{\prime \prime} \mathrm{W}$ & 1825 & 12 June 2000 & 2oroand $10^{7}$ \\
\hline S37 & $28^{\circ} 55^{\prime} 36^{\prime \prime} \mathrm{N}$ & $87^{\circ} 76^{\prime} 68^{\prime \prime} \mathrm{W}$ & 2382 & 13 June 2000 & $10^{7}$ \\
\hline S42 & $28^{\circ} 25^{\prime} 39^{\prime \prime} \mathrm{N}$ & $86^{\circ} 41^{\prime} 33^{\prime \prime} \mathrm{W}$ & 763 & 10 June 2000 & 19 \\
\hline S44 & $28^{\circ} 74^{\prime} 99^{\prime \prime} \mathrm{N}$ & $85^{\circ} 74^{\prime} 77^{\prime \prime} \mathrm{W}$ & 213 & 11 June 2000 & 19and $10^{x}$ \\
\hline
\end{tabular}

\section{Results}

Systematics

Phylum Arthropoda von Siebold, 1848

Class Hexanauplia Oakley, Wolf, Lindgren and Zaharof, 2103

Subclass Copepoda Milne Edwards, 1840

Order Harpacticoida Sars, 1903

Family Cletodidae T. Scott, 1905

Genus Enhydrosoma Boeck, 1872

Enhydrosoma texana sp. nov.

http://zoobank.org/urn:lsid:zoobank.org:act:422F4961-9C3D-467B-BD87-ED82F9A43CFE

Figures 1-6.

Type locality. Station MT $5\left(27^{\circ} 33^{\prime} 28^{\prime \prime} \mathrm{N}, 88^{\circ} 65^{\prime} 60^{\prime \prime} \mathrm{W}\right)$ in the northern Gulf of Mexico, depth $2280 \mathrm{~m}$, on 4 June 2000. Muddy sediment.

Material examined. Holotype: $19($ CR00233171) dissected on 4 slides from the type locality. Paratypes: 1 o dissected on 5 slides (CR00233176) from Station S37; 4 of (CR0023172-CR00233175) dissected on 1 (S36), 3 (S42), 2 (S44) and 6 (S36) slides; $20^{\top} 0^{7}$ (CR0000233177-CR00233178) dissected on 6 (S36) and 2 (S44) slides, respectively. All specimens were collected by W. Lee and R. Kalke. All other details are provided in Table 1.

Etymology. The specific name refers to the type locality, near the Texan coast.

Descriptions. Female: Total body length ranging from 354 to $415 \mu \mathrm{m}(n=5$, mean $=374 \mu \mathrm{m}$; measured from rostral anterior distal margin to posterior margin of caudal rami). Largest width measured at posterior margin of cephalothorax: $108 \mu \mathrm{m}$. Urosome slightly narrower than prosome (Figure 1A).

Cephalothorax with folded lateral sides and with pair of longitudinal ridges dorsally; dorsal surface with serrate posterior margin and few sensilla, covered with minute spinules as illustrated in Figure $1 \mathrm{~A}, \mathrm{C}$. 


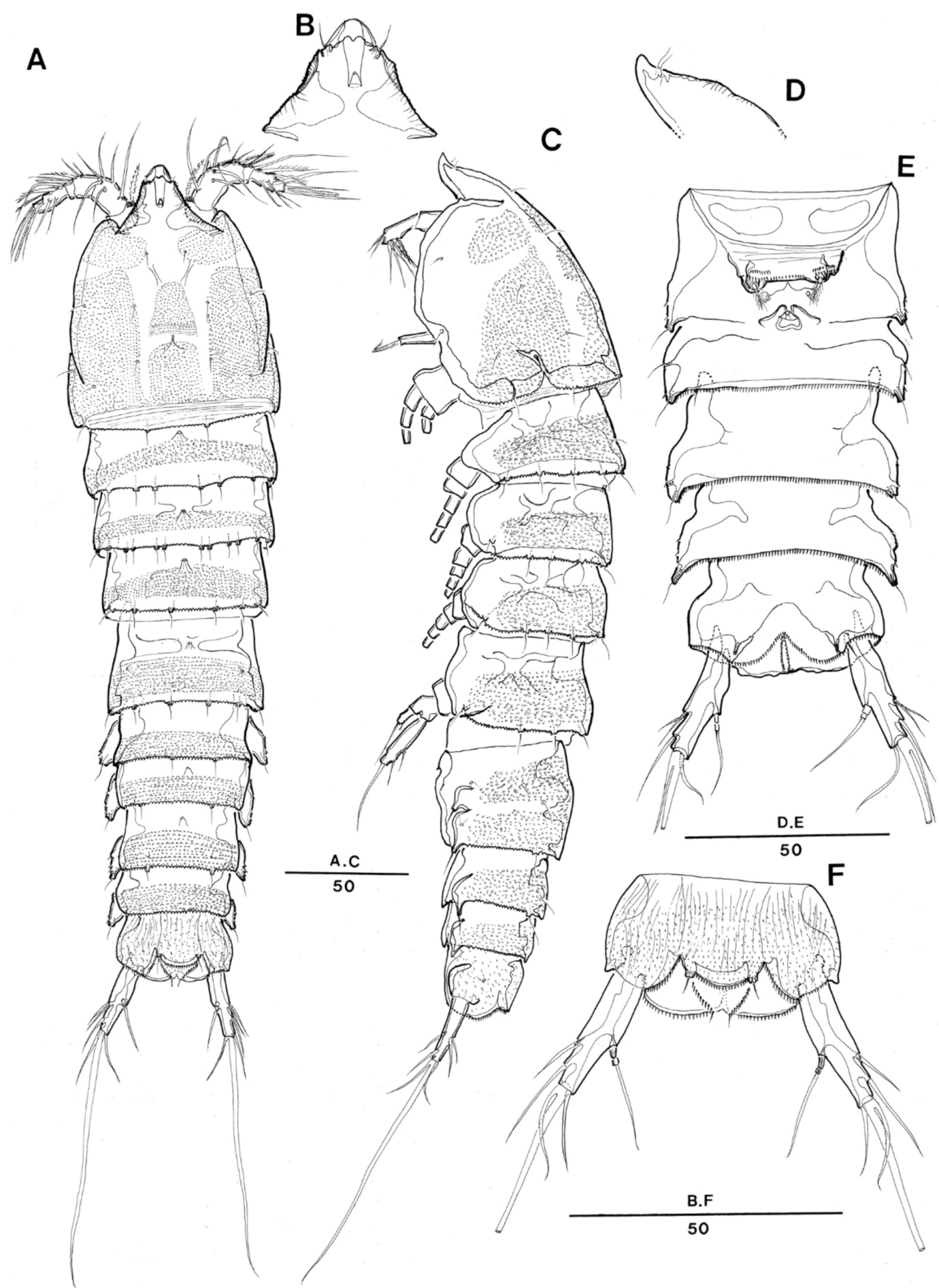

Figure 1. Enhydrsoma texana sp. nov. Female. (A), habitus, dorsal; (B), rostrum dorsal; (C), habitus, lateral; (D), rostrum lateral; (E), urosome, ventral (excluding P5-bearing somite); (F), anal somite and caudal rami, dorsal.

Prosomites (Figure 1A,C) covered with minute spinules and with serrate posterior margins.

Rostrum (Figure 1A-D) well-developed, fused to cephalothorax, triangular, recurved dorsally in lateral view (Figure 1D); round at tip and bearing two sensilla (Figure 1B); median pore on dorsal surface. 


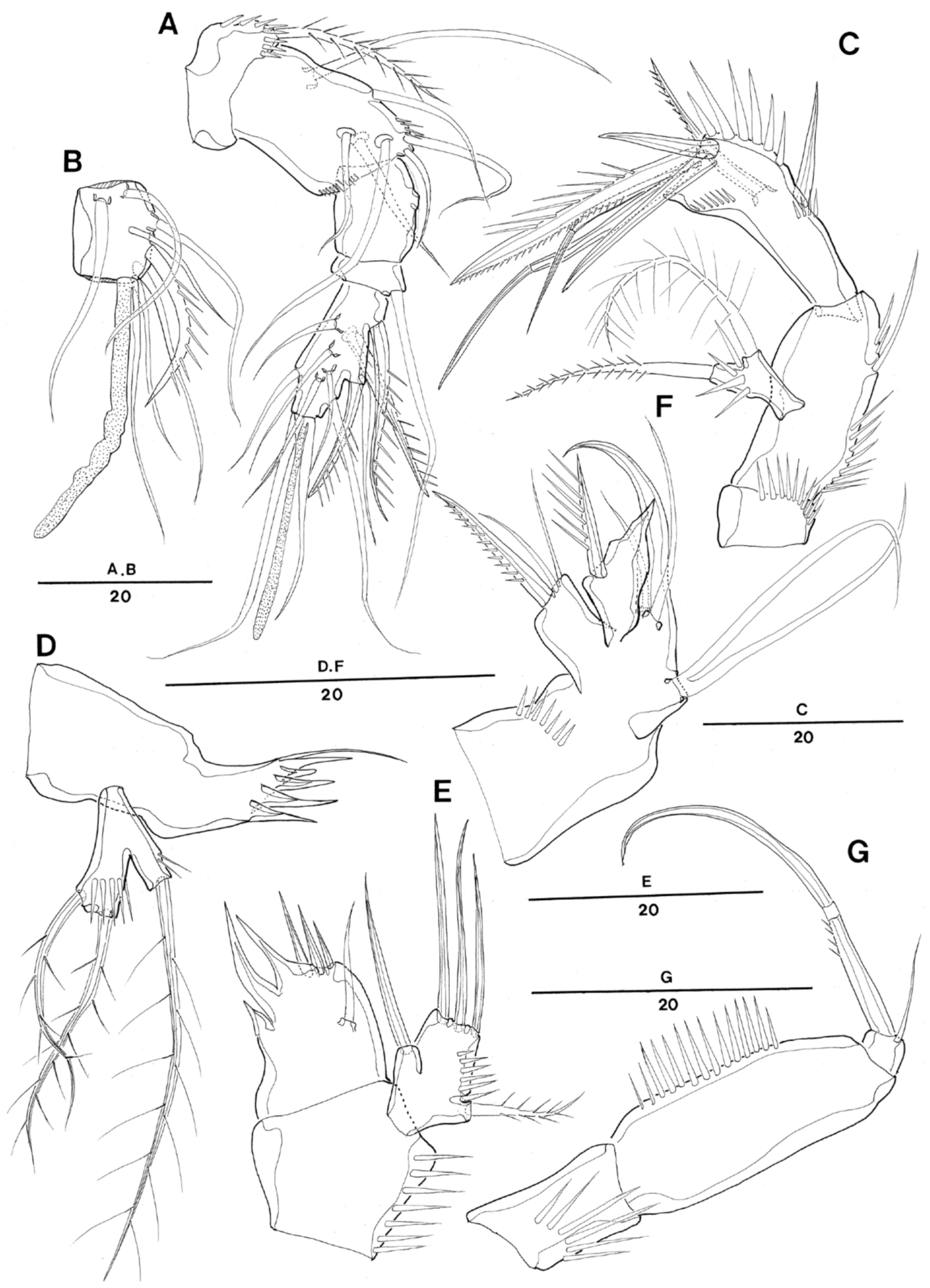

Figure 2. Enhydrosoma texana sp. nov. Female. (A), antennules; (B), 3rd antennulary segment; (C), antenna; (D), mandible; (E), maxillule; (F), maxilla; (G), maxilliped.

Urosomites (Figure 1A,C,E,F) ornamented as illustrated. Dorsal surface and posterior margin of first urosomite ornamented as preceding somites. Second and third urosomites not completely fused and forming genital double-somite. Genital double-somite covered with minute spinules dorsally, with dorsolateral division between second (genital somite) and third urosomites, posterior margin of each urosomites serrate dorsally; each urosomite with several sensilla arising from distinct cones dorsally and laterally as illustrated. 


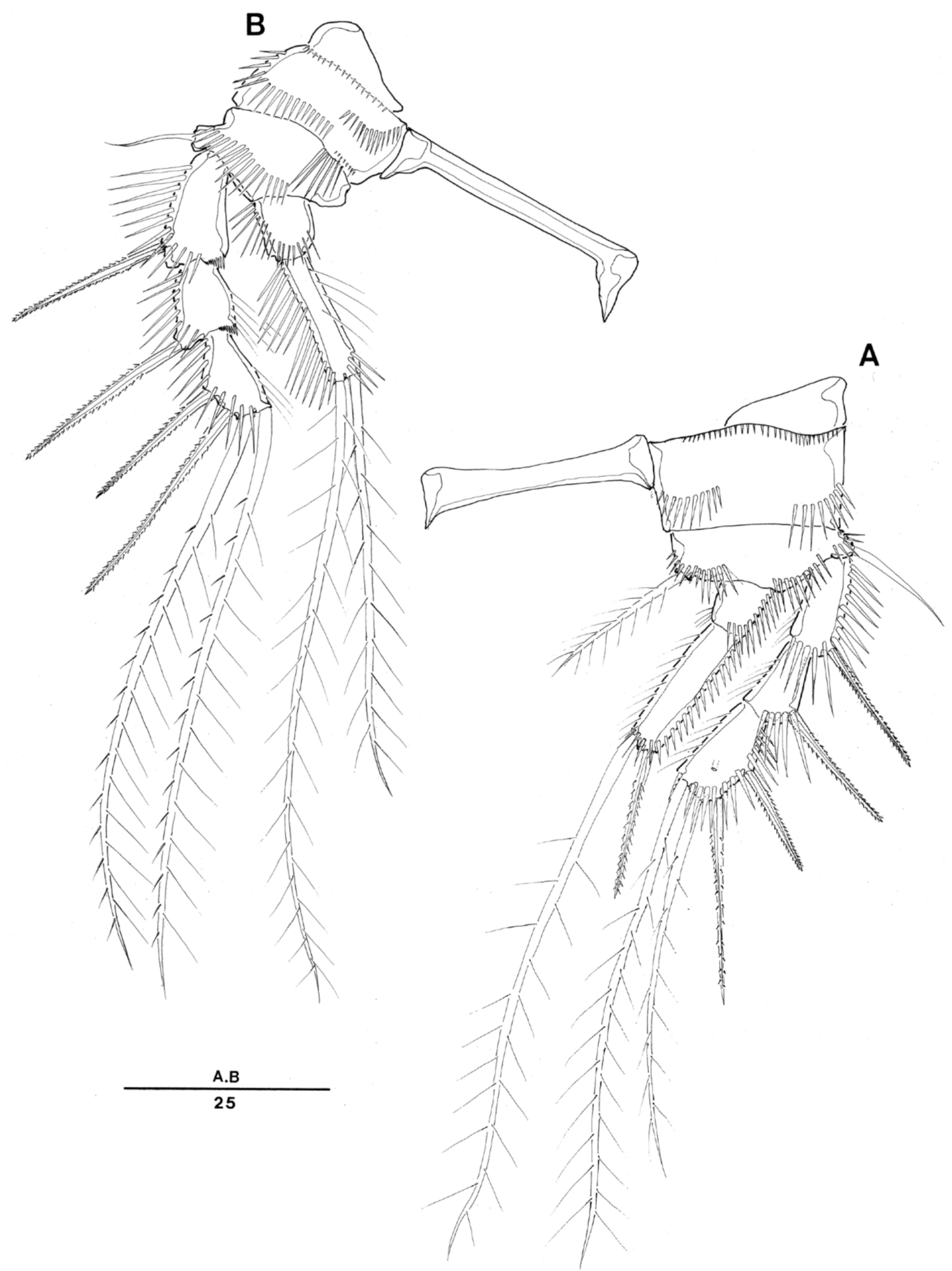

Figure 3. Enhydrosoma texana sp. nov. Female. (A), P1; (B), P2.

Genital area (Figure 1E) located near anterior margin, with single copulatory pore present medially and covered by integumental fold. P6 located in proximal half of first genital somite with small protuberance bearing 1 pinnate seta on each side. First and second genital somites fused mid-ventrally; ventral surface of second genital somite plain, with rows of spinules along posterior and lateral margins.

Anal somite (Figure 1E,F) with patches of minute spinules and fine ridges on dorsal median surface as illustrated. Operculum semicircular, with dentate margin and one sensillum arising from one short socle on each side. Ventral surface smooth without ornamentation, and row of spinules along distal margin. 


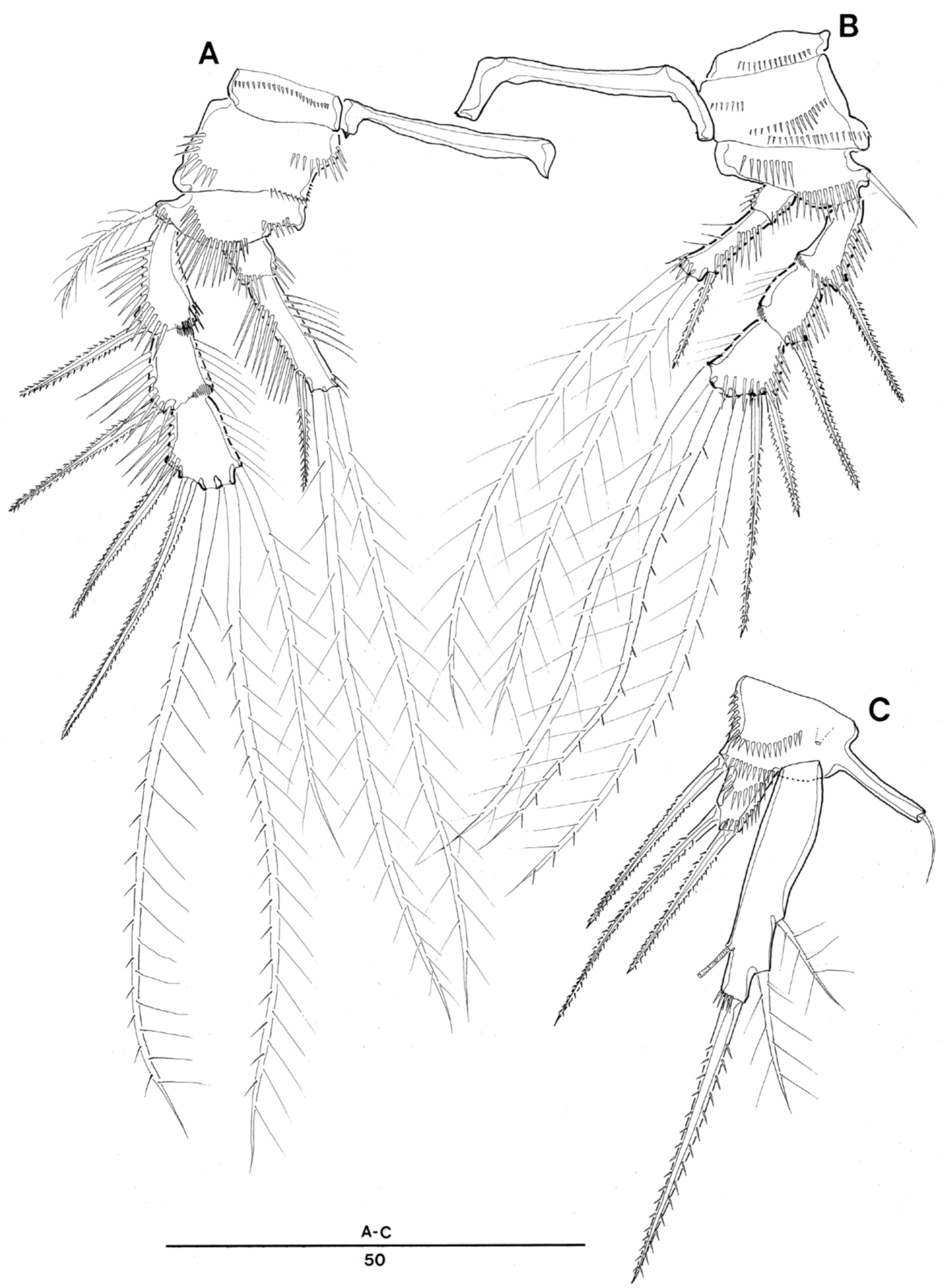

Figure 4. Enhydrosoma texana sp. nov. Female. (A), P3; (B), P4; (C), P5.

Caudal rami (Figure 1E,F) as long as anal somite, and 3.5 times longer than wide; setae I and II arising laterally halfway along outer margin, seta II as long as seta I; seta III twice as long as setae I and II; seta IV small and fused to seta V; seta VI longer than seta II and located on distal inner corner; seta VII bare, located halfway along inner margin of caudal ramus, tri-articulated. 


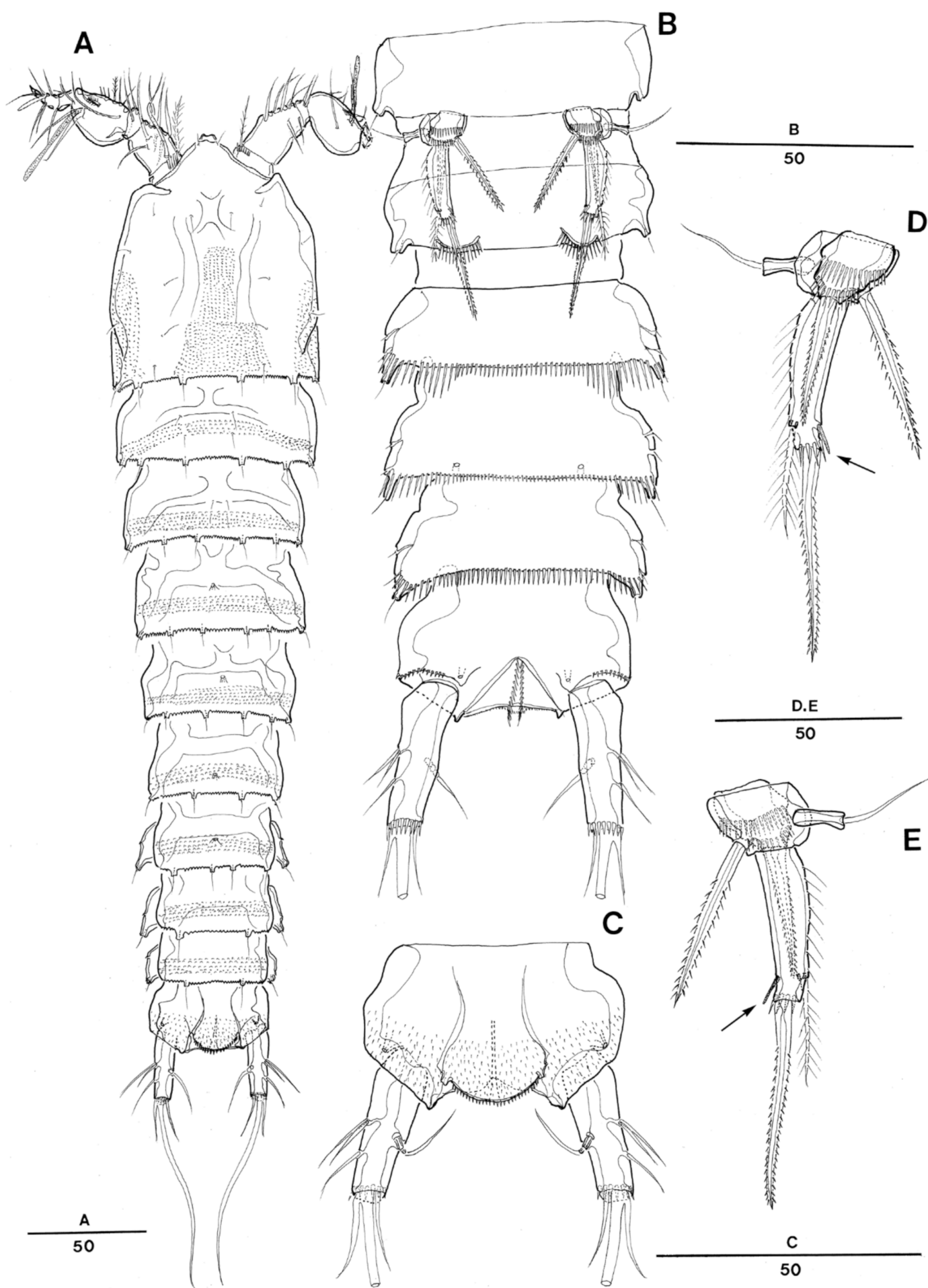

Figure 5. Enhydrosoma texana sp. nov. Male. (A), habitus, dorsal; (B), urosome, ventral view; (C), anal somite and caudal rami, dorsal; (D), P5 posterior view; (E), P5 anterior view.

Antennule (Figure 2A,B) 5-segmented. Segment 1 with lateral and distal row of spinules around anterior margin. Segment 2 largest. Segment 3 with aesthetasc fused basally to 1 seta. All setae smooth except for 1, 1 and 3 pinnate spines on first, third and last segments, respectively. Armature formula: 1-[1 pinnate], 2-[7], 3-[6+1 pinnate+(1+ae)], 4-[1], 5-[8+3 pinnate +1 acrothek]. Apical acrothek consisting of one well-developed aesthetasc fused basally to two slender naked setae. 


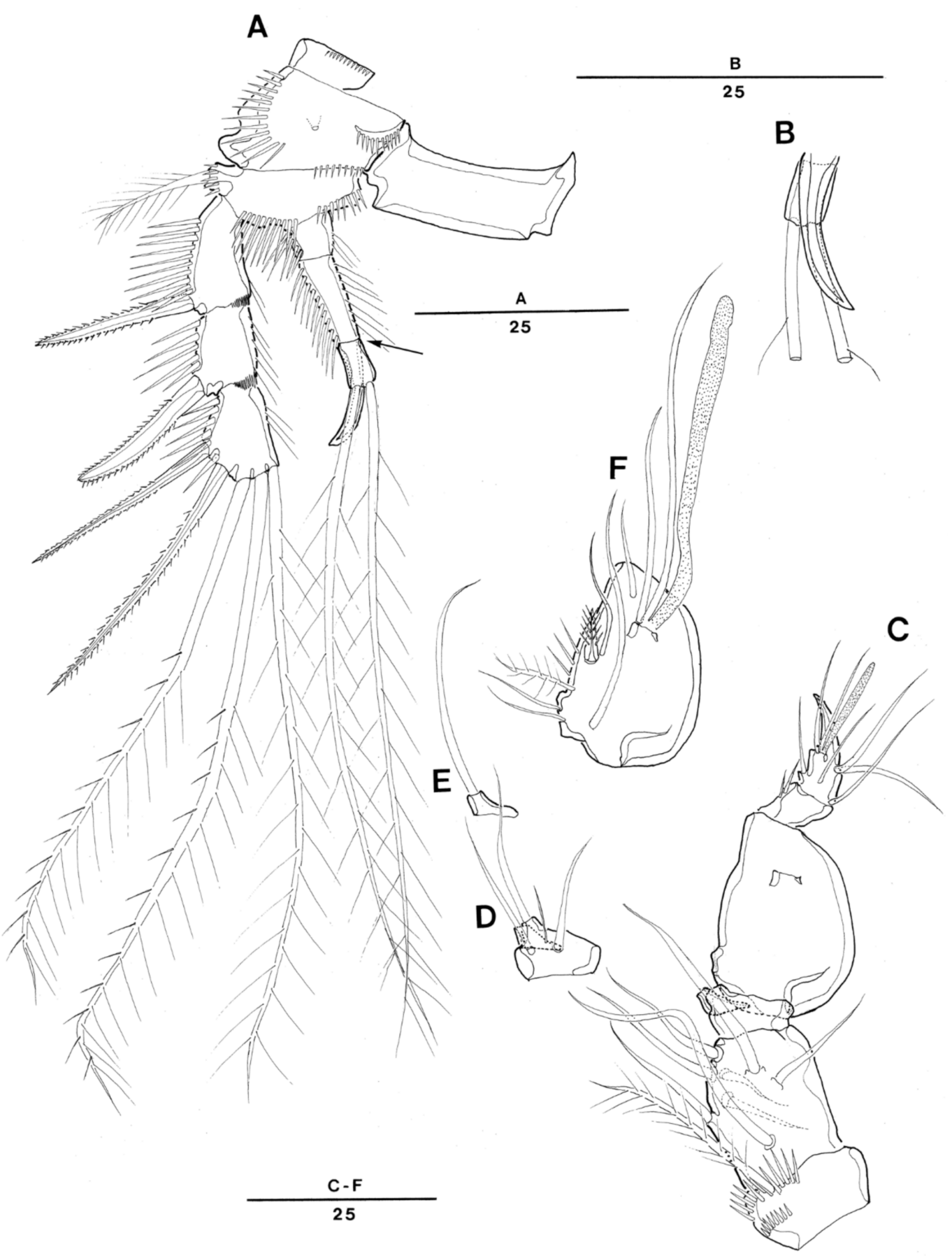

Figure 6. Enhydrosoma texana sp. nov. Male. (A), P3; (B), P3 endopodal apophysis; (C), antennule; (D-F). 3rd, 4th and 5th antennulary segments.

Antenna (Figure 2C) 3-segmented, comprising coxa, allobasis and free 1-segmented endopod. Coxa with one row of spinules along inner margin and one naked abexopodal seta. Exopod 1-segmented, small and bifurcate, with one pinnate seta laterally and one pinnate seta apically; ornamented with spinules. Endopod with row of stout spinules on anterior margin and row of spinules around outer lateral margin; apical armature consisting of one stout pinnate and two naked spines and two geniculate spines; one naked spine and one unipinnate spine laterally.

Mandible (Figure 2D) with well-developed gnathobase bearing multicuspidate teeth and one naked seta at distal corner. Mandibular palp bifurcate1-segmented with one lateral and two distal bipinnate setae; a row of spinules along each ramus; lateral seta originating from cylindrical peduncle. 
Maxillule (Figure 2E) praecoxa with row of spinules along outer lateral margin. Arthrite with three teeth and three strong apical spines and one surface seta. Coxa-basis with three apical and one lateral naked seta; endopod represented by single pinnate seta and one row of spinules along outer lateral surface.

Maxilla (Figure 2F). Syncoxa with one spinular row on anterior surface and two endites; proximal endite with one pinnate spine and two smooth setae; distal endite with one pinnate seta, with distal corner an acute outgrowth. Allobasis produced into long naked curved claw; accessory armature consisting of two slender lateral setae proximally and close to base of endopod. Endopod incorporated into allobasis and represented by two slender setae fused at their base.

Maxilliped (Figure 2G). Syncoxa with one row of spinules. Basis with one row of spinules on palmar region. Endopod small with 1 long, sparsely pinnate claw. Accessory armature consisting of one naked seta.

Swimming legs 1-4 (Figure 3A,B and Figure 4A,B) biramous, with 3-segmented exopod and 2-segmented endopod and with wide intercoxal sclerites and well-developed praecoxae. Coxae and bases with anterior rows of surface spinules as illustrated.

P1 (Figure 3A). Praecoxa triangular with row of short spinules along distal margin. Coxa are large with several rows of spinules on anterior surface and close to outer and inner distal corners.

Basis with one strong, pinnate seta and spinules along inner margin and with one naked seta and several spinules along outer margin. Exopod 3 segmented; exp- 1 and exp-2 with one pinnate spine and outer spinular row without inner spine, respectively; exp-3 with two pinnate outer spines and two pinnate distal setae. Endopod 2-segmented; Enp-1 without seta. Enp-2 about three times longer than enp-1 and with one pinnate stout spine and one slender pinnate seta.

P2-P4 (Figures 3B and 4A,B). Coxae and bases with spinular rows along outer margin. Outer margin of basis with naked seta (P2 and P4) or pinnate seta (P3). Each exopodal segment-1 and -2 with coarse frills at inner distal margin. All segments with rows of spinules and setules as illustrated, especially inner margins of exopod and endopod segments with long setules or spinules.

P2 (Figure 3B) basis with row of spinules on anterior surface. Exopod 3-segmented; exp-3 with two pinnate spines and two plumose setae. Endopod 2-segmented and distal margin of enp-2 reaching to distal margin of exp-3; enp-1 small, with outer spinules and some apical inner spinules; enp-2 with two pinnate setae, outer spinular row, with one row of setules along inner margin and one patch of small spinules inner distally.

P3 (Figure 4A) exp-1 longest with 1 patch of spinules along inner distal margin; exp-2 and exp-3 with row of setules along inner margin. Endopod reaching to middle of exp-3. Enp-2 three times longer than enp-1, with one outer spine and two long apical pinnate setae; both setae subequal in length; one row of setules along inner margin and one row of spinules along outer margin; inner distal corner of enp-2 with one patch of short setules.

P4 (Figure 4B) exopod segments subequal in length; exp-2 and exp-3 with inner row of setules. Endopod reaching to just beyond distal margin of exp-2. Enp-2 three times longer than enp-1. Inner distal corner of enp-2 with 1 patch of short spinules.

Armature formula is as follows:

$\begin{array}{lll} & \text { Exopod } & \text { Endopod } \\ \text { P2 } & 0.0 .022 & 0.020 \\ \text { P3 } & 0.0 .122 & 0.021 \\ \text { P4 } & 0.0 .122 & 0.021\end{array}$

P5 (Figure 4C). Baseoendopod with one long cylindrical outer setophore bearing one terminal seta and one small pore near boundary with exopod. Endopodal lobe reaching about the proximal third of the exopod, ornamented with three transverse rows of long spinules, with one pinnate apical and two pinnate lateral setae. Exopod elongate, somewhat rectangular with row of spinules at base of apical pinnate spine, with two outer setae and one inner tube-pore. 
P6 (Figure 1E), vestigial; each P6 represented by one protuberance bearing one pinnate seta and one row of spinules close to seta insertion area. Copulatory pore located at slightly distal region from median line of genital double somite.

Male: Total body length 364-432 $\mu \mathrm{m}(n=3$, measured from tip of rostrum to posterior margin of caudal rami). Greatest width measured at posterior margin of cephalic shield: $102 \mu \mathrm{m}$.

Prosomites (Figure 5A) slightly narrower than in female, with similar pattern of minute spinules on dorsal surface of each segment as in female. Rostrum less developed than in female, with a smooth and slightly bifid apical margin and one pair of sensilla, as in female (Figure 5A).

Urosomites (Figure 5A,B). Surface ornamentation pattern consisting of patches of minute denticles present dorsally and laterally, with posterior margin irregularly serrate dorsally and laterally. Caudal ramus slightly shorter than in female and three times as long as wide. Sexual dimorphism expressed in A1, P3, P5, P6 and genital field.

Antennule (Figure 6C-F) 7-segmented. Subchirocer. Geniculation present between segments 5 and 6. Segment 1 with two rows of spinules along anterior surface medially and distally. Segment 4 shaped as one small sclerite along anterior margin. Segment 5 swollen and largest. Segment 7 triangular with spinous apical tip. Armature formula: 1-[1 bipinnate], 2-[8], 3-[4], 4-[1], 5-[6+2 pinnate $+(1+$ ae) $], 6-[2], 7-[5+$ acrothek]. Distal acrothek consisted of minute aesthetasc and 2 naked setae.

Mouthparts, $\mathrm{P} 1, \mathrm{P} 2$ and $\mathrm{P} 4$, as in female.

P3 (Figure 6A,B) basis, exp-1 and exp-3 as in female. Exp-2 with one robust and slightly hardened outer spine. Endopod 3-segmented; enp-2 2.2 times longer than enp-1, with one long, outer distal apophysis reaching to tip of third exopodal segment; enp-3 subequal to enp- 1 in length, separated from enp-2 with clear surface suture (arrowed in Figure 6A) but internal articulation obscure, with two long pinnate apical setae.

P5 (Figure 5D,E) baseoendopod same as in female, except for two strong elements only in male P5 and two transverse rows of long spinules; apical pinnate spine overlapped by exopod in ventral view and only reaching to near lateral outer seta of exopod. Exopod elongate, 3.6-times longer than width, with one lateral pinnate outer seta, one apical pinnate strong spine and one inner tube pore (arrowed in Figure 5D,E); one row of setules along outer margin and one spinular row along posterior apical margin.

P6 (Figure 5B), vestigial, represented on both sides by one spinulose ventral plate close to posterior margin of somite; each plate bearing one pinnate apical spine. P6 bearing somite produced into cylindrical process bearing sensillum at each distal outer corner.

\section{Discussion}

We placed the new species in the genus Enhydrosoma on account of two setae on the antennary exopod, one segmented mandibular palp having three elements, the medially elongated segments of the maxilliped, the seta formula and segmentation of swimming legs, the well-developed exopod and enopodal lobe of P5 in both sexes and the well-developed apophysis on P3 enp-2 of the male. All the above character sets can be found from the congeners $[1,5,7,8]$.

Enhydrosoma texana sp. nov. is clearly distinguishable from the type species of the genus, Enhydrosoma curticauda Boeck, 1872, by several character states: (1) the round apical margin of the rostrum in the female (bifid in E. curticauda, see [1], p.86, Figure 1A; P. 89, Figure 4A), (2) the elongated, cylindrical caudal ramus (ovoid in E. curticauda, see [1], p.86-87, Figures 1A,B and 2B), (3) three setae and an inner lateral tube pore on P5 exopod in the female (only four setae in E. curticauda, see [1], p.88, Figure 3A, in addition a long tube pore present on endopodal lobe inner laterally), (4) two setae and an inner lateral tube pore on the exopod in the male (only three setae in E. curticauda, see [1], p.87, Figure 2D, its endopodal lobe has a long tube pore as in the female and elongated with a characteristic triangular shape), (5) a naked abexopodal seta on the antenna (no seta in E. curticauda, see [1], p. 89, Figure 4C), (6) three setae on the mandibular palp (four setae in E. curticauda, see [1], p.89, Figure 4D), (7) no seta on the syncoxa of the maxilliped (a strong pinnate seta in E. curticauda, 
see [1], p.90, Figure 5E), (8) a pinnate seta on the P6 in the female (two elements in E. curticauda, see [1], p.91, Figure 6C), (9) two setae on the P1 enp-2 (three elements in E. curticauda, see [1], p.93, Figure 7A) and (10) three-segmented endopod and the third segment of P3 at least separated by a surface suture (See Figure 6A) in the male (two-segmented in E. curticauda, see [1], p.93, Figure 7B). The oligomerization of seta numbers on the mandibular palp and the syncoxa of maxillipeds, P1, P5 and P6 may be interpreted to mean that E. texana sp. nov. is a more advanced lineage than the type species within the genus. However, E. texana sp. nov. can be accommodated to a primitive basal group within the genus, displaying a combination of plesiomorphic characters: (1) the presence of abexopodal seta on A2, (2) the presence of maxillipedal claw seta, (3) the 3-segmented endopod of male P3, (4) the clearly defined (not fused) exopod and endopod of P5 in both sexes.

Using Wells' key [5], Enhydrosoma texana sp. nov. appears to be most closely related to E. parapropinquum Gómez, 2003. The close relationship between both species is indicated by the following combination of shared character states: (1) an elongated, cylindrical caudal ramus, (2) an abexopodal seta of antennae, (3) the structure of mouth-part appendages including mandible, maxillule, maxilla and maxilliped, (4) seta formula of P1-P4, (5) three setae on the endopod of P5 in the female, (6) overlapping position of the exopod with the endopod in P5 of the male and their setation, (7) only one seta on P6 in the female and (8) the apophysis structure of P3 in the male. Mouthpart appendages, the apophysis of P3 in the male and the appearance of P5 in both sexes is very similar between the two species. These shared characters or potential synapomorphies might reflect a close sister relationship between these two taxa. However, they can be distinguished from one another by the following features. (1) Rostrum: E. texana sp. nov. has a round apical margin in the female (Figure 1A,B) and a bifid apical margin in the male (Figure 5A), while E. parapropinquum has a bifid apical margin in both sexes (See [8], p.96, Figure 1A and p.103, Figure 7). (2) Antennule: the second segment is longest in E. texana sp. nov. (Figure 2A); however, the same segment is clearly shorter than the fifth segment in E. paraproqinquum (see [8], p.98, Figure 3A). (3) Antenna: abexopodal seta is naked in T. texana sp. nov. (Figure 2C), while it is pinnate in E. paraproqinquum (see [8], p.98, Figure 3B). (4) Mandibular palp: the lateral peduncle arming the lateral seta is clearly elongate in E. texana sp. nov. (Figure 2D), while it is barely separated and short in E. paraproqinquum (see [8], p.99, Figure 4A). (5) Maxilliped: the accessory seta on the endopod is slightly shorter than the syncoxa in E. texana sp. nov. (Figure 2G), while it is minute in E. paraproqinquum (see [8], p.99, Figure 3D). (6) P1-P4: enp-2 of P1 and P2 reach to the tip of the exp-3 in E. texana sp. nov. (Figure 4A,B), while these are shorter than their exopods in E. paraproqinquum (see [8], p.100, Figure 5A,B). (7) P3 in males: the shape of the apophysis is sharper apically and smoother laterally in E. texana sp. nov. (Figure 6A,B) than in E. paraproqinquum (see [8], p.105, Figure 9B). (8) P5 in the female: the exopod has one apical and two lateral setae in E. texana sp. nov. (Figure 4C), while it has one apical and three lateral setae in E. paraproqinquum (see [8], p.102, Figure 6C). In addition, the tube pore is inserted laterally in E. texana sp. nov., but it is located rather distally near the proximal area of the apical seta. (9) P5 in the male: exopod located anteriorly against the baseoendopod, the tip of the apical seta reaches only to the middle of the third urosomal somite, and the exopod arises from the apical margin of the baseoendopod in E. texana sp. nov. (Figure 5B-D), while the exopod is located posteriorly, the tip of the apical seta elongates and reaches the middle of the fourth urosomal somite (see [8], p.104, Figure 8), and the exopod arises from the posterior surface in E. paraproqinquum (see [8], p.105, Figure 9C). (10) Caudal ramus: the length of the caudal ramus is 3.5-times longer than the width in the female and 3.0-times longer in the male in E. texana sp. nov. (Figure 1E,F, female; Figure 5A-C, male), while there is no significant difference in the length ratio of the caudal ramus between the female and male in E. paraproqinquum (see [8], p. 97, Figure 2, female; p.104, Figure 8, male).

There are several species that have a P3 with a three-segmented endopod in the male, namely E. texana, E. parapropinquum, E. stylicaudatum Willey, 1935, E. hopkinsi Lang, 1965, E. vicinum Por, 1967, E. littorale Wells, 1967, E. brauchi Coull, 1975, E. herrerai Bell and Kern, 1983 and E. pericoense Mielke, 1990. Gee [1] claimed that the description of the endopod in some species is probably a misinterpretation. Gómez [8] consequently accepted Gee's claim, and he described E. parapropinquum 
as having a two-segmented endopod, although it displays a three-segmented endopod in the published figure (see [8], p.105, Figure 9B). However, we regard the segment as the separated third segment, because it was clearly separated based on our observations of E. texana sp. nov. (Figure 6A,B). Indeed, E. brauchi displays separation of the third endopodal segment marked at the very least by a surface suture (see [12], p.120, Figure 4), as does E. herrerai (see [13], p.902, Figure 3D) and E. pericoense (see [14], P.154, Figure 11A). As Gee (1994) claimed, separation of the third segment can be incomplete; however, it is still quite different from the two-segmented endopods of E. curticauda (see [1], p.93, Figure 7B) and E. coreana Kim, Trebukhova, Lee and Karanovic, 2014 (see [7], P. 259, Figure 8A).

Enhydrosoma species have been described mainly from shallow neritic waters. Gee [1] redescribed E. curticuda based on specimens collected from the muddy sand bottom at depths between 5-50 m from various localities including fjords in Norway and Gullmarfjorden in Sweden. Coull [15] reported E. propinquum from the North Carolina continental shelf at the depth range of $17-41 \mathrm{~m}$. E. brauchi has been reported from the muddy sediment of shallow estuary in the North inlet estuary, Georgetown, South Carolina by Coull [12]. He did not mention the sampling depths of E. brauchi, but the samples are from muddy sediment. Enhydrosoma herrerai is from shallow subtidal habitats in Tampa bay [13]. Enhydrosoma herrerai is collected from fine sands and also Thalassia seagrass beds approximately $0.8 \mathrm{~m}$ deep [13]. Thistle reported two species, E. franklini from subtidal sand of $2 \mathrm{~m}$ depth, Florida and E. woodini from an intertidal Spartina marsh, North Carolina [16]. Based on the previous reports, the genus Enhydrosoma inhabits mainly the shallow subtidal and intertidal zone and adapts to various environments including seagrass beds, sandy and muddy sediments. However, the new species described here was collected from muddy sediment of deep-sea between $213 \mathrm{~m}$ and $2382 \mathrm{~m}$ (Table 1), the deepest habitat that the genus Enhydrosoma has ever been recorded at. The present report enlarges distributional depth of Enhydorosoma from shallow subtidal to deep-sea bathyal zone.

Author Contributions: Conceptualization, W.L. and E.-O.P.; methodology, E.-O.P.; formal analysis, E.-O.P.; investigation, W.L., E.-O.P., and M.R.; writing—original draft preparation, W.L., and E.-O.P.; writing-review and editing, W.L., E.-O.P., and M.R.; visualization, W.L., E.-O.P., and M.R.; supervision, W.L.; project administration, W.L.; funding acquisition, W.L. All authors have read and agreed to the published version of the manuscript.

Funding: This research was conducted under the National Marine Life Collection Program (project) sponsored by the Ministry of Oceans and Fisheries, Korea (MABIK 2014-001-05-04), and the Marine Biotechnology Program (No. 20170431) of the Korea Institute of Marine Science and Technology Promotion (KIMST) funded by the Ministry of Oceans and Fisheries (MOF).

Acknowledgments: The authors wish to express their appreciation to Hee Jin Moon (University of Nevada) for her help in preparing the artwork, and Paul A. Montagna (Texas A\&M University at Corpus Christi) for providing specimens.

Conflicts of Interest: The authors declare no conflict of interest.

\section{References}

1. Gee, J.M. Towards a revision of Enhydrosoma Boeck, 1872 (Harpacticoida: Cletodidae sensu Por); a re-examination of the type species, E. curticauda Boeck, 1872, and the establishment of Kollerua gen. nov. Sarsia 1994, 79, 83-107. [CrossRef]

2. Fiers, F. Redescription of Enhydrosoma lacunae Jakubisiak, 1933 (Copepoda, Harpacticoida); with comments on the Enhydrosoma species reported from West Atlantic localities, and a discussion of cletodid development. Sarsia 1996, 79, 83-107.

3. Gee, J.M. A reappraisal of the taxonomic position of Enhydrosoma curvirostre (Copepoda: Harpacticoida: Cletodidae). J. Mar. Biol. Ass. UK 2001, 81, 33-42. [CrossRef]

4. Gee, J.M.; Huys, R. An appraisal of the taxonomic position of Enhydrosoma buchholzi (Boeck, 1872), E. bifurcarostrum Shen \& Tai, 1965, E. barnishi Wells, 1967 and E. vervoorti Fiers, 1987 with definition of two new genera (Copepoda, Harpacticoida, Cletodidae). Sarsia 1996, 81, 161-191.

5. Wells, J.B.J. An annotated checklist and keys to the species of Copepoda Harpacticoida. Zootaxa 2007, 1568, 1-872. [CrossRef] 
6. Sonmez, S.; Yildiz, I.; Karaytug, S. A new species of Enhydrosoma Boeck, 1872 (Copepoda: Harpacticoida: Cletodidae) from the Black Sea coast of Turkey with some remarks on the taxonomic status of E. wellsi Bodin, 1968. Turk. J. Fish Aquat. Sci. 2018, 19, 817-823.

7. Kim, K.; Trebukhova, Y.; Lee, W.; Karanovic, T. A new species of Enhydrosoma (Copepoda: Harpacticoida: Cletodidae) from Korea, with redescription of E. intermedia and establishment of a new genus. Proc. Biol. Soc. Wash 2014, 127, 248-283. [CrossRef]

8. Gómez, S. Three new species of Enhydrosoma and a new record of Enhydrosoma lacunae (Copepoda: Harpacticoida: Cletodidae) from the Eastern Tropical Pacific. J. Crust. Biol. 2003, 23, 94-118. [CrossRef]

9. Gómez, S. A new species of Enhydrosoma Boeck, 1872 (Copepoda: Harpacticoida: Cletodidae) from Eastern Tropical Pacific. Proc. Biol. Soc. Wash 2004, 117, 529-540.

10. Baguley, J.G.; Montagna, P.A.; Lee, W.; Hyde, L.J.; Rowe, G.T. Spatial and bathymetric trends in Harpacticoida (Copepoda) community structure in the Northern Gulf of Mexico deep-sea. J. Exp. Mar. Biol. Ecol. 2006, 330, 327-341. [CrossRef]

11. Huys, R.; Gee, J.M.; Moore, C.G.; Hamond, R. Marine and Brackish Water Harpacticoid Copepods Part 1. Synopses of the British Fauna (New Series); Field Studies Council: Shrewsbury, UK, 1996; Volume 51, pp. 1-352.

12. Coull, B.C. Three new harpacticoid copepods from the North Inlet Estuary, Georgetown, South Carolina, U.S.A. Crustaceana 1975, 29, 113-126. [CrossRef]

13. Bell, S.S.; Kern, J.C. A new species of Enhydrosoma (Copepoda, Harpacticoida) from Tampa Bay, Florida. Bull Mar. Sci. 1983, 33, 899-904.

14. Mielke, W. Zausodes septimus Lang, 1965 und Enhydrosoma pericoense nov. spec., zweibenthische Ruderfusskrebse (Crustacea, Copepoda) aus dem Eulitoral von Panamá. Microfauna Marina 1990, 6, 139-156.

15. Coull, B.C. Meiobenthic Harpacticoida (Crustacea, Copepoda) from the North Carolina continental shelf. Cah. Biol. Mar. 1971, 12, 195-237.

16. Thistle, D. Enhydrosoma (Copepoda, Harpacticoida): An update and two new species. Trans. Am. Micros. Soc. 1980, 99, 384-397. [CrossRef]

Publisher's Note: MDPI stays neutral with regard to jurisdictional claims in published maps and institutional affiliations.

(C) 2020 by the authors. Licensee MDPI, Basel, Switzerland. This article is an open access article distributed under the terms and conditions of the Creative Commons Attribution (CC BY) license (http://creativecommons.org/licenses/by/4.0/). 